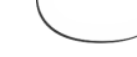

\title{
Interfaces entre os agenciamentos políticos do Estado e das micropolíticas das travestis do Zero na Baixada Cuiabana
}

Haydeé Tainá Schusterı Universidade Federal de Mato Grosso

Resumo: A partir da etnografia realizada no ano de 2018, o presente artigo possui como objetivo articular as interfaces entre a política do Estado e a micropolítica que é agenciada pelas travestis que são trabalhadoras do sexo no Zero. Essas interfaces se dão no relacionamento que as travestis possuem com as políticas de saúde, com a polícia e com a hierarquia interna, que impactam diretamente nas categorias nativas de agressão, violência e transfobia. Para reflexão se faz interessante as discussões oferecidas pela antropologia da saúde através de Didier Fassin, da antropologia urbana por José Guillherme Magnani e da das noções de política molar e molecular, oferecidas por Félix Guattari.

Palavras-chave: Antropologia da Saúde; Antropologia Urbana; Micropolítica; Transfobia; Travestis. 


\title{
Interfaces between the political agencies of the State and the micropolitics of transvestites from Zero in Baixada Cuiabana
}

\begin{abstract}
Based on the ethnography carried out in the year 2018, this article aims to articulate the interfaces between the politics of the State and the micropolitics that is run by transvestites who are sex workers in Zero. These interfaces are found in the relationship that transvestites have with health policies, with the police and with the internal hierarchy, which have a direct impact on the native categories of aggression, violence and transphobia. For reflection, the discussions offered by the anthropology of health through Didier Fassin, of urban anthropology by José Guilherme Magnani and of the notions of molar and molecular politics, offered by Félix Guattari, are interesting.
\end{abstract}

Keywords: Anthropology of Health; Urban Anthropology; Micropolitics; Transphobia; Travestis.

\section{Interfaces entre las agencias políticas del Estado y la micropolítica de travestis de Zero en la Baixada Cuiabana}

\begin{abstract}
Resumen: A partir de la etnografía realizada en el año 2018, el presente artículo tiene como objetivo articular las interfaces entre la política del Estado y la micropolítica que es agenciada por las travestis que son trabajadoras del sexo en el Cero. Estas interfaces se dan en la relación que las travestis poseen con las políticas de salud, con la policía y con la jerarquía interna, que impactan directamente en las categorías nativas de agresión, violencia y transfobia. Para reflexión se hace interesante las discusiones ofrecidas por la antropología de la salud a través de Didier Fassin, de la antropología urbana por José Guilherme Magnani y de las nociones de política molar y molecular, ofrecidas por Félix Guattari.
\end{abstract}

Palabras clave: Antropología de la Salud; Antropología Urbana; micro; transfobia; Travestis. 


\section{O Zero em si}

I

nicialmente, o Zero foi delimitado como um espaço para realizar a etnografia que resultou na dissertação de mestrado, que agora se faz presente neste artigo com um de seus capítulos. Esse território é conhecido pela alta rotatividade de pessoas que trabalham com o mercado do sexo. No que concerne às protagonistas desta pesquisa, as travestis do Zero, elas compreendem a complexa rede de relações que é estabelecida com seus pares e o restante da população como o "mundo de dentro" e "lá fora", que podem ser mediados pelo que pode ser chamado de "mundo do meio".

O Zero é um território localizado na cidade de Várzea Grande (MT), que faz parte da Baixada Cuiabana, devido à proximidade com a capital. O imaginário que circunda a cidade e, em especial, a região conhecida como Zero é de altos índices de violência, tráfico de drogas e prostituição.

Esse medo da violência é efetivo, uma vez que as estimativas apontam para um número considerável de crimes na região, entretanto, o restante da população nutre um imaginário sobre a violência, cercando a região de histórias sobre assaltos, homicídios e tráfico de drogas, muitas vezes colocando como vítima nas histórias a pessoa que vem "de fora" do Zero, enquanto os números apontam para crimes motivados por transfobia e contra prostitutas cisgênero. As pesquisas estatísticas apontam que, em 70\% dos ataques homofóbicos (como são contabilizados), os suspeitos são do gênero masculino e que o segundo crime mais praticado, após a calúnia e difamação, é a lesão corporal ${ }^{2}$. Isso reforça o imaginário de violência, mas que se torna confuso: as principais vítimas são as pessoas que trabalham na região e não o cidadão "de fora".

A região do Zero ficou conhecida assim, pois quando a cidade de Várzea Grande começou a ser urbanizada, o posto de gasolina que havia na rodovia e que leva o nome de "Posto Zero" foi considerado o início da cidade. Na década de 1980, esse posto era o único da região e, por isso, caminhoneiros paravam para pernoitar enquanto mulheres cisgênero já faziam ponto ali3 ${ }^{3}$ Com o aumento de número de motéis na região, o número de trabalhadoras do sexo também aumentou e o território começou a ganhar visibilidade para as pessoas do meio.

Atualmente o Zero é um espaço praticamente no centro da cidade de Várzea Grande, onde se instalaram comércios voltados para mecânica, bares e motéis distribuídos em quatro quadras. Diuturnamente existem pontos de prostituição de mulheres cisgênero e travestis na região, que se organizam entre as ruas. Em 2006, as profissionais que trabalhavam na região reuniram-se por intermédio do Centro de Referência em combate à Homofobia e estabeleceram um código de

${ }_{2}^{2}$ Dados divulgados pelo Grupo Estadual de Combate aos Crimes de Homofobia (GECCH), com levantamento estatístico entre 2011 e 2015 .

3 "Fazer ponto" é a expressão utilizada para quando as trabalhadoras estão na rua esperando algum cliente. O ponto de prostituição só existe quando alguém está ali, por isso ele é "feito”. 
moral e conduta que abrange desde comportamentos, vestimentas, além de permanência ou proibição de acesso a determinadas ruas.

Esse acordo apenas esclareceu e legitimou as organizações internas que as travestis do Zero já possuíam, que culminam na divisão de espaços por meio dessa organização e numa classificação que varia de acordo com as modificações corporais realizadas. Essa classificação é dividida entre "as gays" - algumas travestis falam com artigo feminino, outra no masculino, "os gays", e outras chamam a mesma categoria de "bichas", que é quando o "garoto" homossexual afeminado decide iniciar sua construção como como travesti - as travestis, propriamente ditas, e as "tops". A categoria "gays" pode ser modificada através do tempo de trabalho, quando as bichas vão mudando seus corpos e tornam-se travestis. Isso significa que elas podem ocupar uma rua mais perto da avenida e pontos mais próximos de portas de Motel, enquanto as gays/bichas ficam em pé, normalmente numa esquina ou embaixo de alguma árvore, como explicou Ana4. Quanto mais feminina e mais "natural" forem unhas e cabelos, mais elas se aproximam da Rua Um do Zero, ou "a rua das tops". Além das gays/bichas, travestis e tops, o território é também divido com mulheres cisgênero.

Apesar do constante afronte das bichas em relação às travestis, segundo as regras pré-estabelecidas, a bicha só poderá passar para uma rua mais clara e mais próxima da avenida, caso faça alguma intervenção no corpo, como cirurgia no nariz ou "bombar" 5 peito e bunda, e após trabalhar certo tempo no Zero. É dessa maneira que a performatividade 6 de gênero se constrói a partir do território ocupado e do pertencimento e acaba por constituir as categorias nativas.

Também será mais valorizada se morar em uma das pensões das travestis mais velhas, que acolhem e recebem essas bichas logo que se assumem, quando são expulsas de casa ou saem por conta própria para prostituir-se, ponto que será abordado mais adiante. Por conta disso, além de bichas, travestis e travestis tops, a hierarquia também inclui o símbolo máximo e ascensão: ser dona da pensão onde as travestis moram e administrar os pontos. As donas de pensão do Zero são figuras conhecidas por serem as primeiras a se prostituir na região e abrir espaço dos pontos para travestis. São elas que ocupam o lugar de reconhecimento e, por isso, insinuar que a dona da pensão é uma cafetina ou agenciadora pode gerar grandes conflitos. Essas são as travestis que merecem mais respeito, pois "se dão ao respeito", ou seja, levam a prostituição a sério e não usam o dinheiro para festas e bebida, mas para sobrevivência.

Haraway (2004) e Rubin (1984) compreendem como o gênero também demarca questões de poder e status, que no contexto do Zero são percebidas das relações entre travestis e clientes, travestis e bichas, travestis e donas da pensão. Também são pensadas como os usos desse poder na hierarquia interna e acabam ressoando na questão da violência que existe em relação às bichas e travestis periféricas e, mais ainda, em como a hierarquia se torna importante estratégia de segurança.

A hierarquia interna e a relação com as pessoas que são consideradas do "mundo de fora" contribuem para a categorização de quais atos são considerados agressões, quais são violência e quais são transfobia. O “mundo de dentro" é con-

${ }_{4}^{4}$ Nome fictício de uma das informantes que participaram da pesquisa. Como as informantes permitiram o uso do nome original apenas para dissertação, optamos por nomes fictícios em textos que seriam publicados.

5 Inserir silicone industrial no bumbum e nas coxas. As bombardeiras, como são conhecidas as travestis mais antigas que realizam esse procedimento, possuem um dos papeis mais importantes no processo de construir-se como travesti.

${ }^{6}$ Performance de gênero é compreendida pela autora Judith Butler (2003) em termos genéricos 
siderado a relação entre os pares, as relações hierárquicas internas entre as categorias que as diferenciam, enquanto o "mundo de fora" são os clientes e outros homens que vão até o Zero para praticar atos de violência transfóbica.

\section{Hierarquização e micropolítica}

Partindo do que Guattari (1996: 128) analisa a respeito da micropolítica e de suas relações com a política do Estado, a reflexão acerca de que "as lutas sociais são ao mesmo tempo molares e moleculares" torna-se importante aqui. Isso significa que as lutas molares são travadas entre as camadas, ou seja, as pessoas de fora do Zero e o Estado com as pessoas de dentro do Zero. Já as lutas moleculares se dão no âmago das relações internas e da micropolítica.

Tanto a violência quanto a transfobia possuem categorizações diferentes e significados distintos para as travestis do Zero, sendo distinguidas principalmente pelo objetivo do agente que pratica e por qual a relação desse agente com a vítima (se é uma luta molar ou molecular). Por isso, tanto a micropolítica interna, quanto as relações com as organizações não governamentais servem de base para compreensão do que seria violência e do que seria transfobia.

A micropolítica é pensada por Guattari (1996: 127) como uma "questão analítica das formações do desejo no campo social”. As lutas sociais são molares no sentido das diferenças amplas entre camadas - aqui travestis do Zero e a população cisgênero - ou a violência das pessoas do "mundo de fora"/Estado para o mundo de dentro. Já as moleculares, que envolvem a hierarquia interna e as questões de poder, se dão entre as pessoas do "mundo de dentro". Essa distinção entre o que é molar e o que é molecular torna-se importante na medida em que a categoria violência (ato praticado como consequência a um prévio comportamento da travesti) e a categoria transfobia estão totalmente conectadas a esses níveis.

Essas esferas micro (moleculares) e macro (molares) não se encontram opostas ou separadas, elas tendem a ser encontradas de maneiras simultâneas nos processos de singularização ou de tentativa de representatividade e identidade. Numa situação de agressão a uma travesti, podemos perceber níveis molares de violência - principalmente no que se refere ao agente praticante - e os níveis moleculares - a organização interna estabelece essas diferenças de poder e de abuso dele. Por isso, "toda prática micropolítica consistiria exatamente [em] tentar agenciar processos de singularidade no próprio nível onde eles emergem" (GUATTARI, 1996: 130). Uma análise micropolítica está justamente na interseção das esferas molares e moleculares de uma determinada realidade social.

Em um nível molar, a violência nas narrativas das travestis do Zero está ligada aos clientes que se vingam quando são furtados, ou quando um policial age de maneira agressiva numa revista, ou, ainda, quando existe um suposto motivo prévio para essa violência. A violência que ocorre no nível molar (entre as camadas) é distinta da transfobia em si por conta desse motivo prévio, dado pela própria travesti, enquanto a transfobia é uma agressão de caráter de cunho pessoal, sem nenhum motivo. Embora ambos os casos haja agressão, a violência não possui um caráter de ataque pessoal e só realizada por que foi motivada, enquanto a transfobia possui esse caráter de ataque pessoal.

As agressões passíveis de observação são, na maioria das vezes, físicas e verbais e, para as travestis, só ocorrem por alguns motivos como, por exemplo, o caso das travestis mais periféricas que são acusadas constantemente de arrumarem brigas com clientes e "queimarem" o ponto de prostituição por terem reputação de "barraqueiras". Negar-se a buscar droga para o cliente, quando combinado 
previamente no valor do programa, também pode acarretar em violência. Outras situações que podem ser consideradas gatilhos de violência são as quais as travestis ameaçam expor clientes a público caso não paguem "a mais" que o combinado ou furtam os clientes. Inclusive, nessa mesma categoria de "violência", ainda existe a agressão que parte do segurança particular que, em nome da dona da pensão, pode agir com medidas corretivas caso haja desorganização de espaço.

Quando falam sobre violência, é comum recorrerem a essas situações. Rosa7 sempre que voltava a esse assunto, comentava: "eu já vi muita travesti morrer de graça por vingança de cliente. Por isso tem que ter a disciplina do segurança da dona da pensão para preservar elas mesmas de sofrerem violência depois pela própria rebeldia de não respeitar o espaço e a organização".

A questão da violência recai quase sempre no uso de drogas e medicamentos, uma vez que os furtos a clientes são motivados pela compra de drogas para elas mesmas e esse seria o principal motivador da contrapartida da violência. Também existe um índice bastante alto de uso e prescrição de medicamentos para ansiedade e depressão, que são usados por vezes em substituição às drogas.

Drogas e medicamentos são assuntos pouco falados entre elas e entram mais como forma de acusar outras travestis que "queimam" o ponto do que para compreensão de que existe algum tipo de adoecimento. As travestis tops se vangloriam por não usarem drogas e que esse é um dos principais motivos delas não terem muitos causos de violência em relação aos clientes e que é por serem "limpas" (por não usarem drogas) que conseguiram subir na hierarquia do território.

Contudo, a maioria das tops relata já ter entrado no Zero sendo "apadrinhada” com mais carinho pela dona da pensão. A dona da pensão não é percebida como alguém que use de violência para organizar o território do Zero e as quitinetes, mas sim como a figura que organiza o espaço e disciplina os comportamentos inadequados que gerariam a violência de fato. A agressão da dona da pensão é compreendida como uma medida educativa.

Larissa Pelúcio (2009: 70) explica sobre esse espelhamento do corpo de uma travesti para com a outra e principalmente a questão da identificação com as travestis mais velhas: "Nas esquinas é que as travestis, muitas vezes, têm a sensação de pertencer a algum lugar. Um lugar que começa no corpo de outra travesti" e que se estende à tribo. É como Ana se refere à pensão como uma segunda família que recebe e não julga sua sexualidade, mudança de gênero e trabalho e que cuida para que não sejam violentadas "pelas pessoas do mundo lá fora".

Já as travestis periféricas se consideram rebeldes e nutrem pouca estima pela dona da pensão. Haraway (2004), apesar de referir-se mais às teorias de gênero que explicam o feminismo, compreende as relações de poder que permeiam a transversalidade que o olhar a partir do gênero pode possibilitar. As questões raciais e, principalmente, de região geográfica de origem possibilitam que as tops estejam mais perto do binarismo ${ }^{8}$, sendo geralmente brancas, de família de classe média baixa e alta, sendo também as maiores compactuadoras do papel importante que a dona da pensão possui para a manutenção do sistema hierárquico.

São essas travestis tops que são recorrentemente chamadas para representarem as travestis do Zero em reuniões, propagandas vinculadas à mídia, serem

\footnotetext{
7 Rosa também é nome fictício para uma das informantes que participou da pesquisa. Rosa trabalha no Zero há pelo menos quatro anos e já fez modificações suficientes para trabalhar na "Rua das Tops". Ela é um pouco mais velha que a média das travestis do Zero (45 anos) e também é considerada uma travesti "de respeito" pois leva a prostituição a sério, empenhando-se para obter sempre melhorias no corpo como um investimento no trabalho.

${ }^{8} \mathrm{~A}$ inteligibilidade dos corpos está próxima ao conceito de binarismo. Quanto mais próxima da inteligibilidade homem/ mulher, mais aceita socialmente e maior aceitabilidade em espaços públicos.
} 
porta-vozes das ONGs. Essa questão da representatividade é algo bastante recorrente, uma vez que essas travestis possuem um nível maior de escolaridade e de poder aquisitivo e financeiro. Enquanto isso, a outra parte de maioria esmagadora depende exclusivamente da renda da prostituição para não passar fome e não possuem rede de apoio social alguma que as ampare. Por isso, é comum delas - as travestis periféricas - não quererem se envolver nos assuntos "oficiais" do Zero ou fazer parte de qualquer coletivo que seja, pois não se sentem representadas pelas travestis tops e não querem também "bater de frente" com as que são mais próximas da dona da pensão.

Esse tipo de atrito culmina nas brigas internas, que ocorrem normalmente porque alguma travesti "queimou o ponto" ou tentou se realocar num ponto que não pertence à dona da pensão em que está instalada. Outro motivo de conflito é quando travestis que chegam de outras cidades e ainda não estão instaladas e acabam indo até o Zero sem se importar muito com essa organização, afinal " $a$ rua é pública e ninguém e dona dela", uma fala recorrente. Apesar de todas essas tensões internas, as brigas, a agressividade e ameaça de despejo constante da dona da pensão, não são relações consideradas violentas, pois a violência vem dos clientes e de representantes do Estado, como a polícia, e não do nível molecular (entre seus pares).

Guattari (1996), quando se propõe a pensar na análise de uma micropolítica interna, coloca em questão o modo de como o nível molecular irá reproduzir a subjetividade dominante, percebendo como as diferenças de nível molar são repensadas e reeditadas no nível molecular, que emergem principalmente quando caímos na esfera de um grupo minoritário que discute o que é representatividade. O território do desejo é visto como algo confuso e nebuloso, que precisa ser mediado, na falta do Estado, por uma figura que realize essas mediações - a dona da pensão. Esse conflito interno pode ser pensado e nomeado pela ótica do que Guattari chama de "ruptura de agenciamento": as travestis não podem fazer o que bem entendem, são cerceadas de seus agenciamentos: pela polícia, pela dona da pensão e por seus próprios pares.

Para além da ruptura do agenciamento, a vida de uma travesti é cercada de violência em níveis subjetivos e físicos, de negação a vida social e todos outros direitos de ser reconhecida como pessoa: pela sua família, pela escola, pelo mercado de trabalho. Não é uma surpresa que esse seja o assunto mais recorrente em suas conversas e que haja níveis distintos de interpretação do que é somente agressão, do que é violência e do que é transfobia, afinal, é algo tão constate e corriqueiro que, conforme Rosa:

já estamos calejadas. Tem coisa que estamos tão acostumadas que nem achamos mais que é violência. Transfobia, então, só se houver algo pessoal envolvido. Não adianta se estressar por coisa pequena de agressão, de batida policial e nem de nada.

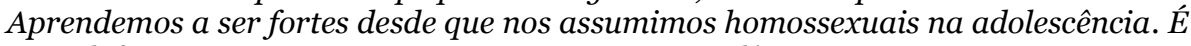
uma defesa nossa não prestar atenção em certas violências.

A antropóloga Veena Das (2011) dedica-se a pensar sobre violência, gênero e subjetividade de forma interseccional e apesar de refletir sobre feminismo e violência de gênero mais propriamente contra mulheres em regiões de conflitos, pauta-se em algumas linhas de pensamento muito interessantes para reflexão acerca do que as travestis do Zero vivenciam e relatam.

É comum a visão da violência como algo extraordinário, pensando o campo da violência constituído de papéis rígidos entre agressor/vítima. Contudo, o que se percebe no Zero é uma distinção: quando se trata de violência, não existe agressor ou vítima, pois houve uma situação prévia em que a travesti praticou algum 
ato transgressor. Já a transfobia é vista como uma violência unilateral, com agressor e vítima, uma vez que ocorre sem situação prévia e possui um caráter de acusação pessoal.

Veena Das (2011) constrói a reflexão acerca da violência percebendo que o tempo possui agência e trabalho. O tempo é capaz de fazer com que a pessoa violentada volte a inserir-se na sociabilidade, torna a pessoa menos vulnerável a atos violentos considerados de menor escala ou que deixam de ser categorizados como violência. Em contrapartida, a existência dessas pessoas e a sobrevivência - algo simples para quem não faz parte desse ciclo de violência - passa a ser considerado um ato de heroísmo. $\mathrm{O}$ gênero e nesse caso o que não é nem reconhecido como gênero, mas como algo além dele - o prefixo trans - demarca de fato a sub-existência dessas pessoas, passa a ser o principal fator que gera violência.

Sobreviver se torna um ato de heroísmo, por isso dificilmente uma travesti irá fazer grandes planejamentos de sua vida. É bem possível que até os 30 anos, faixa etária próxima ao limite de expectativa de vida, vive-se um dia de cada vez e pouco tenha se imaginado num futuro. Não há planejamento de compras de imóveis ou veículos, de fazer graduação ou engajar num relacionamento sério. Diariamente relembram a morte de suas colegas de trabalho e todas elas já perderam alguma parceira de ponto, sem exceções.

Contudo, a vida não se resume à prostituição ou a estarem fadadas a nunca terem planos. Dentro do projeto de vida, cabem algumas alternativas que inserem o status "dona de pensão" dentro do campo de possibilidades. Esse campo de possibilidades pode ser compreendido como um rol de opções de expectativa de vida e de planejamento, dentro dos processos sócio-históricos e dos contextos sociais que movimentam a trajetória de vida do indivíduo social (VELHO, 2003). Por isso, torna-se compreender as relações hierárquicas de poder na micropolítica e como as formas de agressão também impactam no modo de perceber e compreender as trajetórias individuais e pessoais de cada informante dessa etnografia.

\section{Relações com a política do Estado: o nível molar de relações de poder}

Partindo da política molecular que trata das estruturas de poder e da hierarquização internas do Zero, da categorização do que é hostilidade, do que é violência e do que é transfobia, dos modos de existência e resistências possíveis, pela negociação constante da identidade, que se passam no "mundo de dentro", deparamo-nos com outro tipo de violência: a do nível molar, praticada pelo Estado. A agressão em um nível molecular se dá de maneira interna - na micropolítica enquanto a violência está ligada a um nível molar - referente as estruturas do Estado. Apesar da violência praticada pelos representantes do Estado estar ligada à identidade de gênero das travestis, não é algo visto por elas como transfobia.

Essa relação de abjeção do Estado em relação à pessoa trans é bastante refletida por Berenice Bento (2017: 35), percebendo o gênero como uma máquina de produção de corpos binários e que necessitam passar por uma inteligibilidade, tanto em sua estética, quanto estar em consonância com o papel que a reconhece como cidadã - a certidão de nascimento - e que atesta seu gênero. O que se nota é uma "infantilização", nas palavras de Berenice Bento, de negar a capacidade de agência de mulheres trans ou não: "a infantilização e a patologização são retóricas do poder colonial".

Quando a autora se pergunta: "os direitos humanos são para quais humanos?", ela coloca em xeque as categorias "humanos" e "direitos", considerando 
que humano e humanidade não são categorias evidentes e nem constructos naturalizados. Quando uma travesti é vítima de transfeminicídio, o que temos é uma negação da humanidade dessa pessoa e, quando o Estado nega o direito de segurança e de existência a um sujeito inserido na sociedade, empurra as travestis para o abismo da abjeção e, em casos extremos, ao transfeminicídio, negandolhes o direito de serem humanas.

É interessante perceber como o Estado utiliza de grandes categorias como "pessoa trans" para criar leis, deslocando-as de uma realidade dura e violenta, como no caso das travestis, e colando-as em formas tão virtuais que se tornam inacessíveis de serem colocadas em prática como leis. Berenice Bento (2017) entende como a academia tem dividido os sujeitos entre "velhos sujeitos" e "novos sujeitos", enquanto o Estado tem buscado algo bastante semelhante, uma vez que as leis acerca de cotas, identidade de gênero, ações afirmativas para pessoas trans são discussões sobre "novos sujeitos" que não cabem nas leis para "velhos sujeitos".

O dispositivo do medo e da vergonha se mostra quando a vítima consegue sobreviver à violência e não denuncia o agressor, seja porque naturaliza a violência contra si ("ela merece uma punição por não agir de acordo com o esperado") ou mesmo porque sabe que de nada adianta acionar o Estado, demandando justiça via ação criminal (BENTO, 2017: 57).

O que aparece fortemente marcado é que as leis existem no legislativo, mas não são executadas. Isso ocorre porque as leis deveriam ser pensadas em consonância com o coletivo, como uma forma escrita de representação de regras comuns. Inversamente a isso, as leis no Brasil são construídas com o objetivo de criar esse inconsciente coletivo e barrar atitudes de violência que são legitimados em seu âmbito estrutural, como a transfobia. É claro que há o objetivo de que, ao se criar uma lei de combate à transfobia, isso fomente uma consciência sobre o assunto, mas o que percebemos são os arranjos em que a pessoa que pratica o crime realiza para não ser penalizada, pois a lei não representa aquele coletivo (BENTO, 2017).

Enquanto os debates acerca do gênero crescem na academia, o legislativo (em todos os níveis), em contrapartida, recebe a cada eleição, mais e mais deputados conservadores. Esse é só um dos pontos de origem de toda a situação que se reflete no Zero hoje. O transfeminicídio é uma questão recorrente já que no Zero o índice de mortes de travestis é bastante alto, o que corrobora com os índices mencionados inicialmente - um dos países que mais assassina pessoa trans no mundo. A transfobia se inicia no nível material primeiramente: a pessoa trans carrega marcas no seu corpo que são impossíveis de passarem despercebidas, enquanto gays e lésbicas podem "não dar pinta" e passarem despercebidos em situações de perigo eminente. Quando esses crimes ocorrem, grande parte deles tende a ser contabilizados como vítimas gays ou lésbicas.

Em entrevista com Cláudia, a coordenadora do Centro de Referência de Enfretamento à Homofobia (CRDH), que esteve ativamente no Zero entre $2002 \mathrm{e}$ 2008, ela comenta casos nos quais a polícia em investigação apontava a vítima nos autos como gay, descrevendo toda a investigação utilizando os pronomes no masculino. Ao ver as fotos dos autos do processo, Cláudia identificava que se tratava de uma travesti. Um caso que ficou bastante marcante aconteceu em 2006, quando houve o homicídio de uma travesti que costumava atender no Zero. O caso foi notificado como homofobia. Apesar de ela ter se chocado com o uso do termo homofobia para o homicídio de uma travesti, ainda não existia o termo "transfeminicídio" no trabalho dela. 
Ela conta que estava no centro de referência realizando trabalhos administrativos e tentava encaminhar algumas meninas lá do Zero para reabilitação devido ao uso abusivo de substâncias químicas, detectado em atendimentos anteriores. Já havia, inclusive, acionado os familiares dessas garotas cisgênero e trans que estavam nessa situação de vulnerabilidade. Nessa época, a polícia notificava ao $\mathrm{CRDH}$, caso qualquer coisa relacionada às garotas de programa do Zero ocorresse, e o órgão mantinha contato para garantir que nenhum direito dessas pessoas fosse violado pelo Estado.

Nesse momento, as proposições do centro de referência foram a de mudança do gênero que constavam nos autos do processo como masculino, a contabilização da vítima como crime motivado pelo gênero e não pela orientação sexual (como seria no caso de homofobia) e o uso do nome social toda vez que o processo se referisse à vítima. É interessante perceber que a peça de uso exclusivamente feminino - a calcinha - foi crucial para definição do gênero da vítima e desvelar a motivação do crime.

\section{O dispositivo da travestilidade: as agências dos próprios corpos}

O processo de modificação corporal para uma travesti é totalmente atrelado à sua existência, enquanto identidade de gênero e pessoa. Enquanto estiver viva, procedimentos de modificação corporal serão realizados, como a fala recorrente da interlocurtora Dani9: "se eu parar de mexer no meu corpo é por que estou morta”. Por isso, a relação delas com o saber biomédico ${ }^{10}$, que regulamenta seus corpos e oferece esses procedimentos dentro da normatização, é algo que merece atenção.

Uma das modificações realizadas e que realmente as coloca no "mundo das travestis" é a hormonização. Essa é uma das primeiras modificações que são "internas". Enquanto as outras mudanças estão ligadas a unhas, cabelo e maquiagem, a hormonização é um procedimento irreversível e que é colocado "dentro" do corpo. Esse é também o momento inicial da relação entre travestis e médicos, uma vez que a hormonioterapia é oferecida pela rede pública de saúde e realizada por profissionais da saúde, após avaliações psicológicas e socioeconômicas. Contudo, não é um serviço procurado pelas travestis do Zero, sendo mais usual que mulheres transexuais o utilizem.

Para realizar a hormonioterapia, existe a necessidade de enquadramento no Manual de Diagnósticos e Doenças Mentais - o DSM V - no que é reconhecido como "transtorno de Disforia de Gênero", que compreende essa "disforia” como uma identificação com o sexo oposto, não se reconhecendo no corpo biológico. Do DSM IV para o DSM V, revisto em 2013, a mudança do termo "transtorno de identidade de gênero" para "disforia de gênero", retirou a homossexualidade e a transexualidade da condição de patologias - apesar de ainda fazerem parte de um manual de diagnóstico de doenças. Contudo, a travestilidade continua no quadro geral de patologias ligadas a identidade e personalidade.

Esses fatores contribuem para que as pessoas que se considerem transexuais aceitem essa nomenclatura e, inclusive, se apoderem do discurso acerca da disforia de gênero para combater ataques transfóbicos. Já as travestis, que ainda estão categorizadas como portadoras de uma patologia, negam totalmente a disforia de

9 Uma das principais interlocutoras dessa etnografia. Dani trabalha no Zero há alguns anos e já está na Rua das Tops.

${ }^{10}$ Ciência médica tradicional que produz a "verdade" sobre os corpos. 
gênero e não utilizam esse discurso para autodefesa, uma vez que o próprio discurso já as condena. Por não serem percebidas dentro da disforia ${ }^{11}$ de gênero e, em contrapartida, não haver identificação com nenhuma das definições que o termo "disforia" carrega, elas optam em não acessar os serviços formais de saúde que necessitam desse enquadramento para realizar atendimento (BENTO, 2017).

Os laudos utilizados pelos profissionais da saúde precisam necessariamente atestar que existe um desconforto do indivíduo em relação ao seu corpo para ter acesso aos procedimentos estéticos. Mas a noção de corpo perpassa apenas a um órgão: a genitália. Fassin e Rechtman (2009) compreendem a noção de "trauma" como algo recorrente na identificação dos sujeitos pelo Estado. A necessidade de mediadores que produzam provas concretas e que atestem esse "trauma" para assim significar a experiência ao sujeito que se submete ao saber biomédico e, nesse caso, a transexualidade necessariamente precisa ser atestada através de "eventos traumáticos".

Essas apropriações das técnicas do saber biomédico e que se tornam agenciamento em relação às modificações corporais, que se encontra com as técnicas que são utilizadas para exercer o poder sobre seus corpos, são expressas tanto pela política quanto pela própria tecnologia médica que, em contrapartida, se apropria das técnicas de cada um em relação aos seus corpos (FASSIN, 2004). Então, por mais que o Estado exerça o poder sobre os corpos, não existe de fato uma via unilateral e horizontal de poder, mas, sim, uma contaminação de práticas de ambos os lados.

As questões tratadas pelo Estado no que se refere às travestis que trabalham no Zero está focada nas questões que consideram "de saúde" - reduzir números de doenças - sendo essas suas ações diretas. Contudo, as resoluções do Estado afetam-nas e retiram seus meios de existência como pessoa, restando a prostituição como via de reconhecimento do outro para constituir-se como pessoa. A biopolítica exercida pelo Estado foi interpretada por Fassin (2009) como a política que governa a vida e, dentro desse sistema, a medicina passa a ser pensada como um sistema cultural que age a partir sempre de um ponto de vista do processo de adoecimento e a enfermidade de maneira individual.

As reflexões pautadas no que é ser homem ou mulher de maneira instituída e que, consequentemente, chegam até a circulação de poder, também permeiam o que é ser uma travesti "de verdade". O dispositivo transexual então se pautaria na produção de corpos inteligíveis, partindo do princípio que pessoas trans necessariamente possuem o desejo de readequação de suas genitálias, como supõe o CID 10 e o DSM V, e que estaria em sofrimento ao não se adequar totalmente, virando uma pessoa trans "de verdade" (BENTO, 2012). Podemos resgatar a noção de "trauma", pautada por Fassin e Rechtman (2009), para compreender o motivo de o Estado precisar de uma comprovação de sofrimento.

A noção de trauma pode ser compreendida como um motivo de intervenção do Estado sobre os corpos, como uma maneira de produzir dados materiais acerca da insatisfação com o próprio sexo para, então, a partir da confirmação do sofrimento dos indivíduos, intervir também. Contudo, para as travestis, a genitália não é o que define seu gênero, mas os seios e a bunda, dotados do simbolismo do feminino. O uso da terminologia "dispositivo", então, se torna bastante coerente na medida em que demonstra esse assujeitamento às normas biomédicas de determinação da transexualidade, em que se "chegou ao ponto de negociar a própria condição de sujeito" (BENTO, 2017, p. 150).

${ }^{11}$ Não há consenso ainda sobre os usos da terminologia "disforia" estar carregada ainda de estigma e da necessidade de laudos com enquadramento para realização da cirurgia transgenitalizadora. 
O dispositivo da travestilidade perpassa o cotidiano de pessoas trans de maneira mais clara e opressiva do que o dispositivo da sexualidade se faz presente na vida vivida de pessoas cisgênero:

\begin{abstract}
A patologização significa que você precisa seguir protocolos e alguém precisa assinar um documento confirmando que você é quem você afirma ser [...]. O Ministério da Saúde oferece uma carteira que reconhece sua identidade de gênero, sem perguntar nada sobre a cirurgia, sem perguntar se a pessoa passou ou quer passar pela cirurgia. Apenas reconhece [...]. Por que então eu preciso de um protocolo para alterar meus documentos oficiais de identificação? (BENTO, 2017: 160)
\end{abstract}

Esse paradoxo demonstra de tal maneira, o quanto o dispositivo da travestilidade está engendrado no Estado e não se dá de maneira coerente. A obsessiva busca e preocupação por uma identidade essencial fixa, como problematiza Bento, faz com que o Estado ora assuma o posicionamento de contribuir para que a identidade seja o mais rápido possível reestabelecida e que fique transparente e ora reprime para que haja coerência.

O dispositivo da travestilidade perpassa de uma maneira ainda mais complicada pelo Estado, uma vez que não há o desejo de consonância e uma suposta adequação dos corpos ao gênero performado socialmente. A coerência cobrada pelo Estado, que se torna minimamente possível no dispositivo da transexualidade, é impraticável quando a questão são os agenciamentos dos corpos e da existência das travestis.

Recebido em 17 de junho de 2019.

Aprovado em 15 de outubro de 2019.

\title{
Referências
}

AMERICAN PSYCHIATRIC ASSOCIATION. Diagnostic and Statistical Manual of Mental Disorders: Fifth Edition (DSM-V). Arlington, VA: America.

BENTO, Berenice Alves de Melo. A diferença que faz a diferença: corpo e subjetividade na transexualidade. Revista Bagoas (UFRN), 4: 95-112, 2009.

O que é transexualidade? Coleção primeiros passos. $2^{\mathrm{a}}$ ed, São Paulo: Editora Brasiliense, 2012.

EDUFBA, 2017.

Transviad@s: gênero, sexualidade e direitos humanos. Salvador:

BUTLER, Judith. "Corpos que pesam: sobre os limites discursivos do sexo" (1993). In: LOURO, Guacira Lopes (org.). O Corpo Educado. 3ed. Belo Horizonte: Autêntica Editora, 2016. 
DELEUZE, G; GUATTARI, F. O que é Filosofia? São Paulo: Editora 34, 1993.

FASSIN, Didier; RECHTMAN, Richard. The Empire of Trauma: an inquiry into the condition of victimhood. Princeton: Princeton University Press, 2009.

FASSIN, Didier. Entre las políticas de lo viviente y las políticas de la vida. Revista Colombiana de Antropologia, 40: 238-318, 2004.

FOUCAULT, Michel. História da sexualidade. Rio de Janeiro: Graal, 1997.

Segurança, território, população: Curso dado no Collège de France (1977-1978). São Paulo: Martins Fontes.2008.

GUATTARI, Félix. Micropolítica: cartografias do desejo. Petrópolis: Editora Vozes, 1996.

HARAWAY, Donna. Gênero para um dicionário marxista: a política sexual de uma palavra. Cadernos Pagu (Unicamp), 22: 221-246, 2004.

MAGNANI, José Guilherme Cantor. A antropologia Urbana e o desafio da metrópole. Tempo social (USP), 15 (1): 81-95, 2003.

PELÚCIO, Larissa. Abjeção e desejo: uma etnografia travesti sobre o modelo preventivo de aids. São Paulo: Anablume, 2009.

RUBIN, Gayle. "Pensando o Sexo: Notas para uma Teoria Radical das Políticas da sexualidade (1984)”. In: RUBIN, Gayle. Políticas do Sexo. São Paulo: Ubu Editora, 2017.

SILVA, Hélio R. S. Travestis: entre o espelho e a rua. Rio de Janeiro: Rocco, 2007.

VELHO, Gilberto. Projeto e metamorfose: antropologia das sociedades complexas. Rio de Janeiro: Jorge Zahar, 2003. 


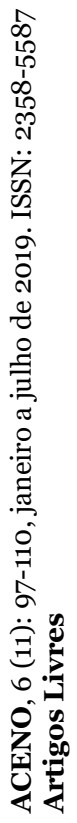

110 